\title{
Downregulation of expression of transporters associated with antigen processing 1 and 2 and human leukocyte antigen $I$ and its effect on immunity in nasopharyngeal carcinoma patients
}

\author{
YAN-XIN REN ${ }^{1, *}$, JIE YANG $^{1, *}$, LI-JUAN ZHANG ${ }^{2}$, RUI-MEI SUN ${ }^{1}$, LIU-FANG ZHAO ${ }^{1}$, \\ MING ZHANG $^{3}$, YUN CHEN ${ }^{2}$, JING MA $^{4}, \mathrm{KUN}$ QIAO $^{1}$, QIANG-MING SUN $^{5}$, \\ HAI-TING LONG ${ }^{5}$, YUN-CHAO HUANG ${ }^{6}$ and XIAO-JIANG LI ${ }^{1}$
}

\begin{abstract}
${ }^{1}$ Head and Neck Tumor Research Center; Departments of ${ }^{2}$ Pathology and ${ }^{3}$ Radiotherapy, The Third Affiliated Hospital of Kunming Medical University, Kunming, Yunnan 650118; ${ }^{4}$ Department of Otolaryngology, Kunming Children's Hospital, Kunming, Yunnan 650034; ${ }^{5}$ Institute of Medical Biology, Chinese Academy of Medical Sciences; ${ }^{6}$ Department of Cardiothoracic Surgery, The Third Affiliated Hospital of Kunming Medical University, Kunming, Yunnan 650118, P.R. China
\end{abstract}

Received April 10, 2013; Accepted July 31, 2013

DOI: $10.3892 / \mathrm{mco} .2013 .194$

\begin{abstract}
The human leukocyte antigen (HLA)-I and antigen-processing machinery (APM) are crucial in the anticancer immune response. The aim of this study was to assess the clinical significance of the APM components [transporters associated with antigen processing (TAP)-1 and -2 and HLA-I] in nasopharyngeal carcinoma (NPC). A total of 58 NPC specimens and 20 healthy specimens used as control were evaluated by semiquantitative immunohistochemistry for three APM components (TAP-1, TAP-2 and HLA-I). The expression of the APM components in NPC was downregulated. $\mathrm{CD}^{+}$and $\mathrm{CD}^{+} \mathrm{T}$ cells were measured by flow cytometry and IL-10 was measured by ELISA. The number of $\mathrm{CD}^{+} \mathrm{T}$ cells and the expression of IL-10 were higher and the number of $\mathrm{CD} 4{ }^{+} \mathrm{T}$ cells was lower in NPC, compared to the controls. The number of $\mathrm{CD}^{+} \mathrm{T}$ cells and the expression of IL-10 were negatively correlated with TAP-1, TAP-2 and HLA-I expression. The clinical phase, lymph node metastasis, distant metastasis, pathological type, TAP-1 expression, TAP-2 expression and HLA-I expression were identified as prognostic factors by the Kaplan-Meier analysis. A multivariate analysis using a Cox regression model indicated that distant metastasis and the downregulation of HLA-I expression were independent unfavorable prognostic factors. In conclusion, the lower expression
\end{abstract}

Correspondence to: Professor Xiao-Jiang Li, Head and Neck Tumor Research Center, The Third Affiliated Hospital of Kunming Medical University, 519 Kunzhou Road, Kunming, Yunnan 650118, P.R. China

E-mail: xiaojiangle@yahoo.com.cn

*Contributed equally

Key words: nasopharyngeal neoplasms, transporter associated with antigen processing 1 , transporter associated with antigen processing 2 , human leucocyte antigen I of HLA-I induced immunosuppression in NPC patients and was associated with a poor prognosis.

\section{Introduction}

Viruses and tumors evade cytotoxic T lymphocyte-mediated host immunity through the downregulation of antigen-presentation machineries. This may be achieved by either the downregulation of transcription of antigen presentation genes, or the post-translational inactivation of the proteins involved in antigen presentation (1). The optimal cell surface expression of human leukocyte antigen (HLA) molecules requires the coordinated expression of several genes, such as transporters associated with antigen processing (TAP)-1 and -2, low molecular weight peptide (LMP)-2 and -7 and tapasin, as well as HLA class I heavy chain and $\beta_{2}$-microglobulin $\left(\beta_{2} M\right)$. In cases of concurrent tumorigenesis and viral infection, the expression of these genes and the function of the encoded proteins are often impaired.

Latent Epstein-Barr virus (EBV) infections are associated with lymphocyte and epithelial cell malignancies, with nasopharyngeal carcinoma (NPC) being the most frequent EBV-associated malignancy (2). The EBV-associated, undifferentiated form of NPC exhibits the most consistent association with EBV worldwide and is particularly common in China and Southeast Asia, reaching a peak incidence of $\sim 20-30$ cases per 100,000 individuals (3). In addition to genetic predisposition, EBV infection and environmental factors, such as dietary and geographic components, were considered to be important in the aetiology of NPC (4-6). Previous studies that used quantitative polymerase chain reaction to measure circulating tumor-derived EBV DNA in the blood of NPC patients demonstrated that the level of pre-treatment EBV DNA was significantly associated with overall survival and that post-treatment EBV DNA levels predicted progression-free and overall survival $(7,8)$. Previous studies on normal nasopharyngeal tissue and premalignant biopsies indicated that genetic events occur early in the pathogenesis of NPC and they may predispose to subsequent EBV 
infection. The EBV latent-gene expression in NPC is predominantly restricted to the Epstein-Barr nuclear antigen 1, the latent membrane proteins (LMP) 2A and 2B and the BamHI-A transcripts, with approximately $70 \%$ of the tumors also expressing the oncogenic LMP1 protein (9-11).

Currently, research is focused on the mechanisms underlying the escape of NPC from EBV-specific immune destruction and the development of novel strategies for immune intervention. BamHI-C fragment rightward reading frame 1 (BCRF-1) that is located in the EBV gene, is able to produce viral interleukin-10 (vIL-10), which is the homologue of the human IL-10 (hIL-10). In EBV-infected B lymphocytes, vIL-10 and hIL-10 are equally capable of downregulating TAP-1 expression, thereby interfering with the loading of major histocompatibility complex (MHC) class I molecules, resulting in empty and unstable MHC class $\mathrm{I} / \beta_{2} \mathrm{M}$ complexes. The BCRF- 1 gene and the vIL-10 protein are highly expressed in NPC tissues (data not shown); therefore, we aimed to assess whether the expression of TAP-1, TAP-2 and HLA-I are affected in NPC and investigate whether these proteins may be prognostic factors for NPC.

\section{Materials and methods}

Case specimens. A total of 78 paraffin specimens (biopsy specimens obtained during surgery) from 58 patients and 20 healthy controls were collected from the Pathology Department of The Third Affiliated Hospital of Kunmming Medical University, between 2000 and 2002. The characteristics of the 58 patients are summarized in Table I. The control group comprised 20 healthy individuals who were examined at the hospital and NPC was excluded by pathological examination. Immunohistochemistry confirmed that all the specimens were collected prior to medical treatment. Peripheral blood $(2 \mathrm{ml})$ was collected from each patient in heparin tubes. Approval for this study was granted by the Ethics Committee of The Third Affiliated Hospital of Kunming Medical University. The patients provided their permission for the collection of the specimens. The NPC patients received medical treatment according to the NCCN Practice Guidelines for Head and Neck Cancer following pathological diagnosis. All the patients were followed up after treatment.

Immunohistochemistry. Rabbit polyclonal anti-TAP-1 antibody (1:100 dilution; Santa Cruz Biotechnology Inc., Santa Cruz, CA, USA), rabbit monoclonal anti-HLA-I antibody (1:250 dilution; Epitomics Inc., Burlingame, CA, USA) and rabbit polyclonal anti-TAP-2 antibody (1:100 dilution; Abcam, Hong Kong, China) were used in this study. Specimens used as the positive contrast were purchased from Beijing Zhongshan Golden Bridge Biotechnology Co., Ltd. (Beijing, China) and phosphate-buffered saline (PBS) was used for negative contrast. Tumor sections $(4 \mu \mathrm{m})$ were deparaffinised and heated in a microwave oven for $10 \mathrm{~min}$ for antigen repair. After cooling, the slides were submerged in a peroxidase quenching solution containing 1 part of $30 \%$ hydrogen peroxide to 9 parts of absolute methanol for $10 \mathrm{~min}$ and were then washed with PBS. Subsequently, $10 \%$ serum was added to each section, followed by incubation for $20 \mathrm{~min}$ and draining. The sections were incubated with the primary antibodies overnight in a $4^{\circ} \mathrm{C}$ chamber, then rinsed with PBS. After rinsing, the sections were treated with
Table I. Characteristics of study population in NPC $(n=58)$.

\begin{tabular}{lc}
\hline Case & No. $(\%)$ \\
\hline Gender & \\
Male & $38(65.5)$ \\
Female & $20(34.5)$ \\
Age (years) & \\
Mean (range) & $49.23(14-84)$ \\
Clinical stage & \\
I & $4(6.9)$ \\
II & $18(31.0)$ \\
III & $10(17.3)$ \\
IV & $26(44.8)$ \\
Histological differentiation & \\
High or moderate & $5(8.6)$ \\
Poor & $53(91.4)$ \\
Lymph node metastasis & \\
$\mathrm{N}_{0}$ & $17(29.3)$ \\
$\mathrm{N}_{1-3}$ & $41(70.7)$ \\
Distant metastasis & \\
$\mathrm{M}_{0}$ & $48(82.8)$ \\
$\mathrm{M}_{1}$ & $10(17.2)$ \\
\hline
\end{tabular}

NPC, nasopharyngeal carcinoma.

biotin-conjugated antibody for $10 \mathrm{~min}$ followed by washing with PBS. Horseradish peroxidase polymer conjugate was applied to each section and incubated for $10 \mathrm{~min}$, followed by washing with PBS. Finally, 3,3'-diaminobenzidine was applied to each section and incubated for $10 \mathrm{~min}$. The samples were rinsed thoroughly with distilled water. Subsequently, the slides were counterstained with hematoxylin, dehydrated and sealed with neutral gum.

The staining of the cores was scored based on signal intensity (0-3) and the percentage of positive cells $(0,<5 \% ; 1,5-10 \%$; $2,11-50 \% ; 3,51 \%-80 \%$; and $4 \geq 50 \%$ ) (12). The results defined as positive were scored based on the product of the two data as follows: 0 , negative (-); 1-4, weak positive $(+) ; 5-8$, medium positive $(++)$; and 9-12, strong positive $(+++)$.

Flow cytometry (FCM). The collected peripheral blood cells were immunostained with fluorochrome-conjugated anti-human antibodies (FITC-conjugated anti-human CD4, PE-conjugated anti-human CD4 and PC5-conjugated anti-human CD45; Beckman Coulter Inc., Brea, CA, USA) for $25 \mathrm{~min}$ at $4^{\circ} \mathrm{C}$. The peripheral blood was dissolved using Q-prep autohemolysis equipment. The samples were analyzed with a flow cytometer (EPICS-XL; Beckman Coulter Inc.). The frequency of $\mathrm{CD}^{+}{ }^{+} \mathrm{T}$ cells $(\mathrm{CD} 4-\mathrm{FITC} / \mathrm{CD} 45-\mathrm{PC} 5)$ and $\mathrm{CD}^{+} \mathrm{T}$ cells (CD8-PE/CD45-PC5) among the lymphocytes of different subsets was calculated, with IgG-FITC/CD45-PC5 and IgG-PE/CD45-PC5 as the negative controls. Data was analyzed with Expo32 software.

Measurement of IL-10 by enzyme-linked immunosorbent assay (ELISA). The blood samples were centrifuged at 3,000 rpm 
Table II. Expression of TAP-1, TAP-2 and HLA-I in the NPC and the control group.

\begin{tabular}{|c|c|c|c|c|c|c|c|c|c|c|}
\hline \multirow[b]{2}{*}{ Group } & \multirow[b]{2}{*}{ No. } & \multicolumn{2}{|c|}{ TAP-1 } & \multirow[b]{2}{*}{ P-value } & \multicolumn{2}{|c|}{ TAP-2 } & \multirow[b]{2}{*}{ P-value } & \multicolumn{2}{|c|}{ HLA-I } & \multirow[b]{2}{*}{ P-value } \\
\hline & & - & + & & - & + & & - & + & \\
\hline $\begin{array}{l}\text { Chronic } \\
\text { inflammation }\end{array}$ & 20 & 2 & 18 & $<0.001$ & 1 & 19 & $<0.001$ & 1 & 19 & $<0.001$ \\
\hline NPC & 58 & 33 & 25 & & 31 & 27 & & 29 & 29 & \\
\hline
\end{tabular}

TAP, transporters associated with antigen processing; HLA, human leukocyte antigen; NPC, nasopharyngeal carcinoma. The Chi-square values were $13.22,14.43$ and 12.72 , respectively.

Table III. Association of TAP-1, TAP-2 and HLA-I expression with clinical factors in NPC.

\begin{tabular}{|c|c|c|c|c|c|c|c|c|c|}
\hline & \multicolumn{2}{|c|}{ TAP-1 } & \multirow[b]{2}{*}{ P-value } & \multicolumn{2}{|c|}{ TAP-2 } & \multirow[b]{2}{*}{$\mathrm{P}$-value } & \multicolumn{2}{|c|}{ HLA-I } & \multirow[b]{2}{*}{ P-value } \\
\hline & $\begin{array}{c}\text { Positive } \\
\text { no. }(\%)\end{array}$ & $\begin{array}{c}\text { Negative } \\
\text { no. }(\%)\end{array}$ & & $\begin{array}{c}\text { Positive } \\
\text { no. }(\%)\end{array}$ & $\begin{array}{c}\text { Negative } \\
\text { no. }(\%)\end{array}$ & & $\begin{array}{c}\text { Positive } \\
\text { no. }(\%)\end{array}$ & $\begin{array}{c}\text { Negative } \\
\text { no. }(\%)\end{array}$ & \\
\hline \multicolumn{10}{|c|}{ Age (years) } \\
\hline$\leq 43$ & $12(48)$ & $16(48.5)$ & 1.00 & $15(55.5)$ & 13 (41.9) & 0.43 & $10(34.5)$ & $18(62.1)$ & 0.065 \\
\hline$>43$ & $13(52)$ & $17(51.5)$ & & $12(44.4)$ & $18(58.1)$ & & $19(65.5)$ & $11(37.9)$ & \\
\hline \multicolumn{10}{|l|}{ Gender } \\
\hline Male & $17(68)$ & $21(63.6)$ & 0.786 & $16(59.3)$ & $22(71)$ & 0.413 & $20(69)$ & $18(62.1)$ & 0.783 \\
\hline Female & $8(32)$ & $12(36.4)$ & & $11(40.7)$ & $9(29)$ & & $9(31)$ & $11(37.9)$ & \\
\hline \multicolumn{10}{|l|}{$\begin{array}{l}\text { Clinical } \\
\text { stage }\end{array}$} \\
\hline $\mathrm{I}+\mathrm{II}$ & $13(52)$ & $7(21.2)$ & 0.015 & $15(55.6)$ & $5(16.1)$ & 0.002 & $15(51.7)$ & $5(17.2)$ & 0.012 \\
\hline III+IV & $12(48)$ & $26(78.8)$ & & $12(44.4)$ & $26(83.9)$ & & $14(48.3)$ & $24(82.8)$ & \\
\hline \multicolumn{10}{|c|}{$\begin{array}{l}\text { Lymph node } \\
\text { metastasis }\end{array}$} \\
\hline Yes & $11(44)$ & $30(90.9)$ & 0.00 & $12(44.4)$ & $29(93.5)$ & 0.00 & $13(44.8)$ & $28(96.6)$ & 0.00 \\
\hline No & $14(56)$ & $3(9.1)$ & & $15(55.6)$ & $2(6.5)$ & & $16(55.2)$ & $1(3.4)$ & \\
\hline \multicolumn{10}{|c|}{$\begin{array}{l}\text { Distant } \\
\text { metastasis }\end{array}$} \\
\hline Yes & $1(4)$ & $9(27.3)$ & 0.033 & $1(3.7)$ & $9(29)$ & 0.014 & $0(0)$ & $10(35.7)$ & 0.00 \\
\hline No & $24(96)$ & $24(72.7)$ & & $26(96.3)$ & $22(71)$ & & $29(100)$ & $19(64.3)$ & \\
\hline
\end{tabular}

TAP, transporters associated with antigen processing; HLA, human leukocyte antigen; NPC, nasopharyngeal carcinoma.

(825 x g) for $25 \mathrm{~min}$. The supernatant was collected, aliquoted and stored at $-80^{\circ} \mathrm{C}$ until use. The concentrations of IL-10 were measured using commercial ELISA kits (Biosource International Inc., Boshide Company, Wuhan, China), according to the manufacturer's instructions.

Statistical analysis. Data were analyzed using SPSS software, version 12.0 (SPSS Inc., Chicago, IL, USA). The correlation of TAP-1, TAP-2 and HLA-I expression with the clinicopathological variables was performed with the Chi-square test. The expression of $\mathrm{CD}^{+} \mathrm{T}$ cells, $\mathrm{CD}^{+} \mathrm{T}$ cells and IL-10 in the different groups was assessed with the independent-samples t-test. Survival was assessed with the Kaplan-Meier analysis and the log-rank score was used for determining statistical significance. The relative risk was assessed with the multivariate Cox proportional hazards model. $\mathrm{P}<0.05$ was considered to indicate a statistically significant difference.

\section{Results}

Low TAP-1, TAP-2 and HLA-I expression in NPC tissue. In NPC, the TAP-1 and TAP-2 immunoreactivity displayed weak diffuse cytoplasmic staining, whereas HLA-I displayed weak diffuse cytoplasmic and cytomembranous staining (Fig. 1A, C and E). By contrast, normal nasopharyngeal tissues exhibited intense staining for these proteins (Fig. 1B, D and F). A total of 25, 27 and 29 of the 58 NPC samples exhibited low expression of TAP-1, TAP-2 and HLA-I, respectively, whereas 18, 19 and 19 of the 20 normal nasopharyngeal tissue samples exhibited 

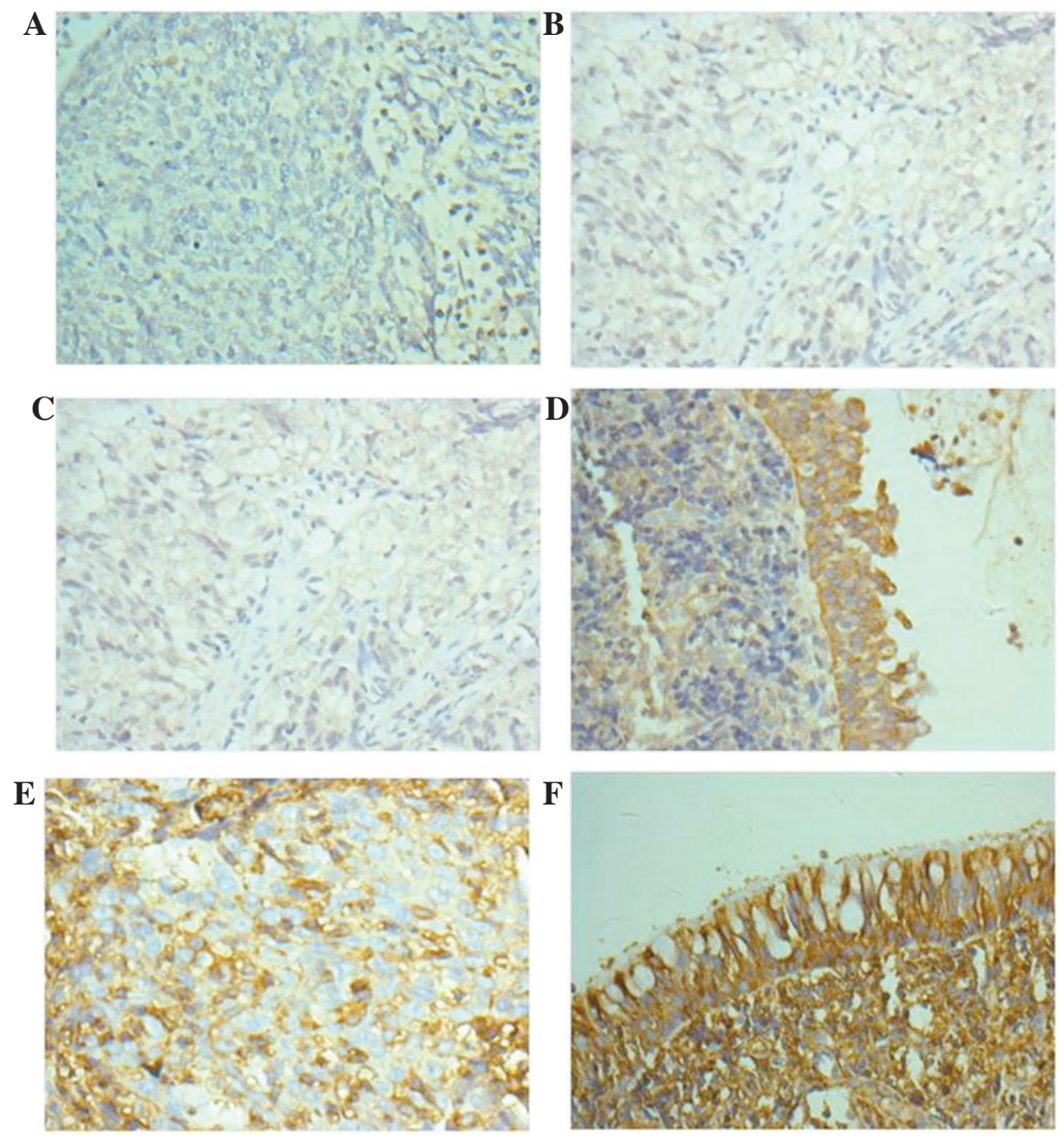

Figure 1. Expression of TAP-1, TAP-2 and HLA-I in NPC and normal nasopharyngeal tissue samples. Staining for the three proteins was performed as described in Materials and methods. NPC tissues exhibited weak positive or absent staining for (A) TAP-1, (C) TAP-2 and (E) HLA-I (magnification, x400). Normal nasopharyngeal tissues exhibited strong staining for (B) TAP-1, (D) TAP-2 and (F) HLA-I (magnification, x400). TAP, transporters associated with antigen processing; HLA, human leukocyte antigen; NPC, nasopharyngeal carcinoma.

A

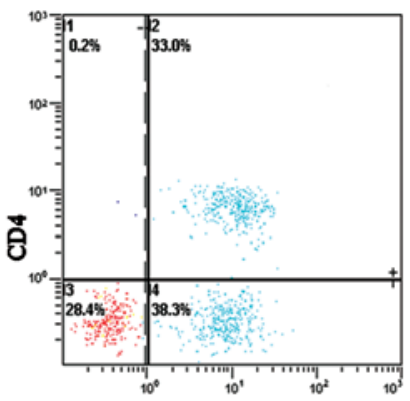

C

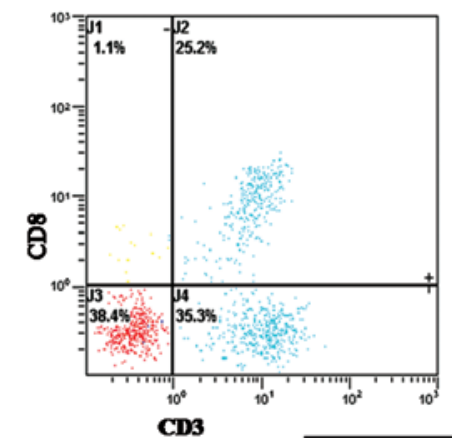

B

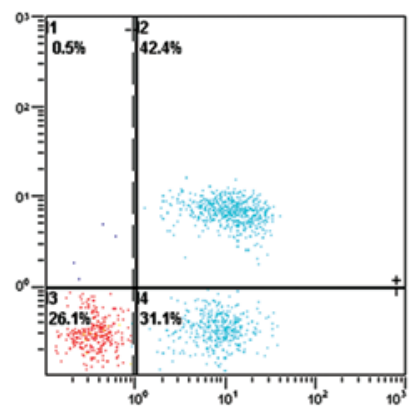

D

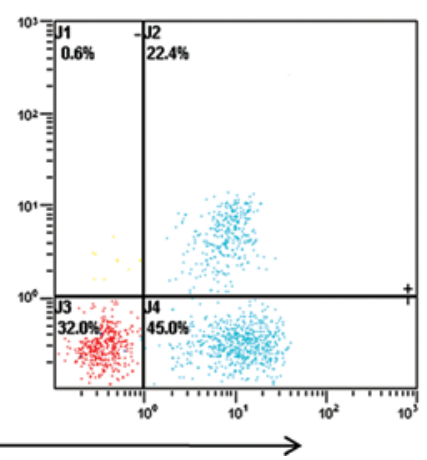

$\mathbf{E}$

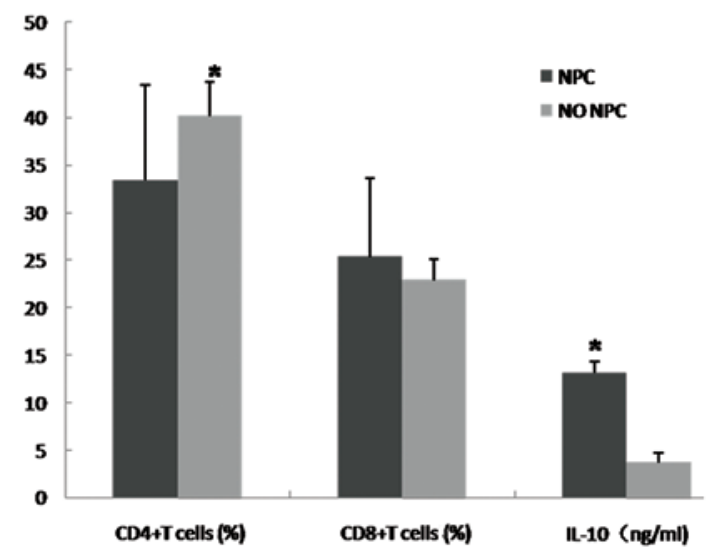

Figure 2. Percentage of $\mathrm{CD}^{+}$and $\mathrm{CD} 8^{+} \mathrm{T}$ cells to peripheral blood (PB) lymphocytes in NPC and control samples. The percentage of $\mathrm{CD} 4^{+}$and $\mathrm{CD} 8^{+} \mathrm{T}$ cells was analyzed by flow cytometry. The percentage of $\mathrm{CD}^{+} \mathrm{T}$ cells in NPC (A) was $33.0 \%$, whereas in the control group (B) it was $42.4 \%$. The percentage of $\mathrm{CD}^{+} \mathrm{T}$ cells in NPC (C) was $25.2 \%$ and in the control group (D) it was $22.4 \%$. A representative experiment is shown. (E) The percentages of CD4 ${ }^{+} \mathrm{T}$ cells, $\mathrm{CD}^{+} \mathrm{T}$ cells and the expression of IL- 10 were assessed with independent-samples t-test in the NPC and control groups. " $\mathrm{P}<0.05$ was considered to indicate a statistically significant difference. NPC, nasopharyngeal carcinoma; NO NPC, normal nasopharyngeal tissues. 
Table IV. Analysis of CD4 ${ }^{+} \mathrm{T}$ cells, $\mathrm{CD}^{+} \mathrm{T}$ cells and IL-10 expression in different TAP-1, -2 and HLA-I expression groups in NPC.

\begin{tabular}{|c|c|c|c|c|c|c|c|c|c|}
\hline & \multicolumn{2}{|c|}{ TAP-1 } & \multirow[b]{2}{*}{ P-value } & \multicolumn{2}{|c|}{ TAP-2 } & \multirow[b]{2}{*}{ P-value } & \multicolumn{2}{|c|}{ HLA-I } & \multirow[b]{2}{*}{ P-value } \\
\hline & Positive & Negative & & Positive & Negative & & Positive & Negative & \\
\hline $\mathrm{CD}^{+} \mathrm{T}$ cell $(\%)$ & $33.19 \pm 9.20$ & $33.35 \pm 8.05$ & 0.970 & $33.58 \pm 6.40$ & $32.52 \pm 5.20$ & 0.815 & $34.34 \pm 6.58$ & $30.22 \pm 3.49$ & 0.379 \\
\hline $\mathrm{CD}^{+} \mathrm{T}$ cell $(\%)$ & $27.93 \pm 4.04$ & $18.43 \pm 2.37$ & 0.013 & $28.47 \pm 3.62$ & $19.18 \pm 2.11$ & 0.018 & $31.35 \pm 4.72$ & $16.65 \pm 2.07$ & 0.005 \\
\hline IL-10 (ng/ml) & $9.87 \pm 1.24$ & $16.20 \pm 1.48$ & 0.021 & $8.93 \pm 0.56$ & $16.04 \pm 1.75$ & 0.015 & $6.28 \pm 0.86$ & $17.99 \pm 2.01$ & 0.008 \\
\hline
\end{tabular}

TAP, transporters associated with antigen processing; HLA, human leukocyte antigen; NPC, nasopharyngeal carcinoma; IL, interleukin.

A

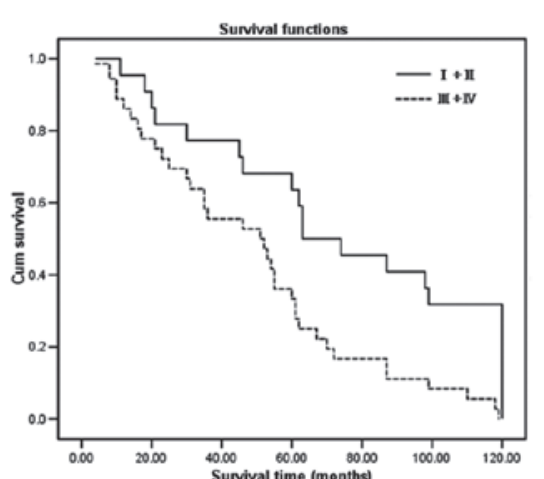

B

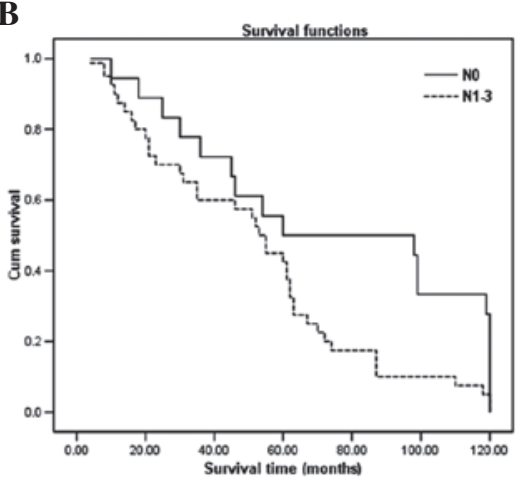

C

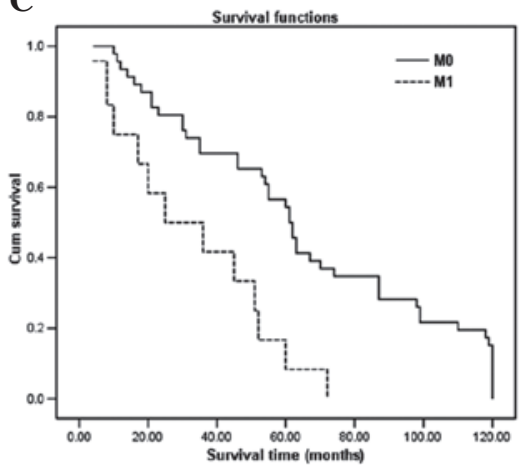

D

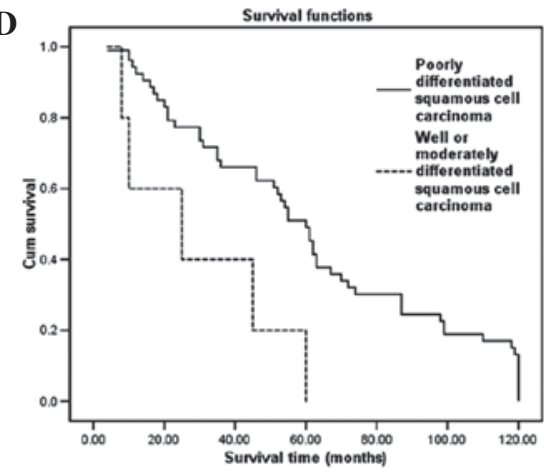

F

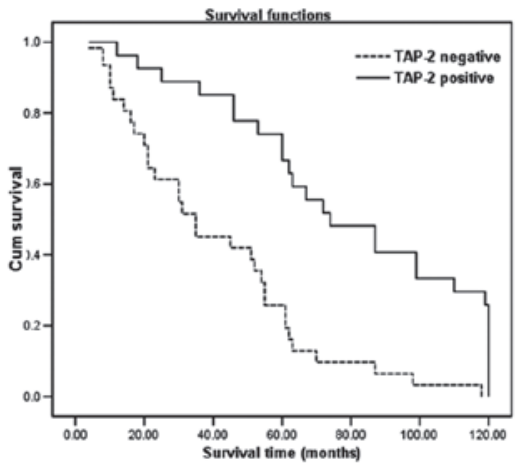

E

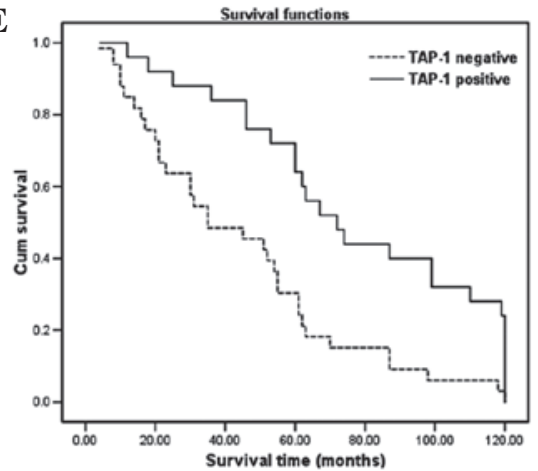

G

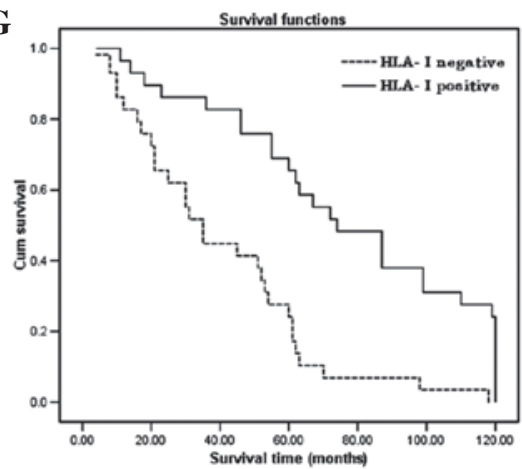

Figure 3. Kaplan-Meier curves for survival by different clinicopathological factors. (A) NPC patients with stage I+II disease exhibited significantly higher survival rates compared to those with stage III+IV disease. (B) and (C) NPC patients with lymph node or distant organ metastases exhibited lower survival rates compared to those without lymph node or distant organ metastasis. (D) Poor histological differentiation was associated with higher survival rates compared to high or moderate differentiation. (E), (F) and (G) NPC patients with positive expression exhibited higher survival rates compared to those with negative expression of TAP-1, TAP-2 and HLA-I. NPC, nasopharyngeal carcinoma; TAP, transporters associated with antigen processing; HLA, human leukocyte antigen; Cum, cumulative.

high expression of TAP-1, TAP-2 and HLA-I, respectively. Therefore, the expression of TAP-1, TAP-2 and HLA-I in the NPC samples was distinctly lower compared to that in the normal nasopharyngeal tissue samples $(\mathrm{P}<0.05$, Table II).
Changes in $C D 4^{+} T$ cells, $C D 8^{+} T$ cells and IL-10 in the peripheral blood of NPC patients. FCM was applied to detect $\mathrm{CD}^{+}{ }^{+} \mathrm{T}$ cells, $\mathrm{CD} 8^{+} \mathrm{T}$ cells and IL-10 was analyzed by ELISA. The percentage of $\mathrm{CD} 4^{+} \mathrm{T}$ cells in the peripheral 
Table V. Univariate survival analysis in patients with NPC.

\begin{tabular}{|c|c|c|c|c|c|}
\hline Factor & No. & 3-year survival rate $(\%)$ & 5-year survival rate $(\%)$ & Log-rank value & P-value \\
\hline \multicolumn{6}{|l|}{ Age (years) } \\
\hline$\leq 43$ & 38 & 68.42 & 47.37 & 1.63 & 0.202 \\
\hline$>43$ & 20 & 60.00 & 40.00 & & \\
\hline \multicolumn{6}{|l|}{ Gender } \\
\hline Male & 38 & 79.50 & 65.00 & 0.26 & 0.610 \\
\hline Female & 20 & 71.05 & 44.74 & & \\
\hline \multicolumn{6}{|l|}{ Clinical stage } \\
\hline $\mathrm{I}+\mathrm{II}$ & 22 & 77.27 & 56.25 & 10.14 & 0.001 \\
\hline III+IV & 36 & 55.56 & 38.89 & & \\
\hline \multicolumn{6}{|l|}{$\mathrm{N}$ stage } \\
\hline $\mathrm{N}_{0}$ & 17 & 76.47 & 47.06 & 5.36 & 0.021 \\
\hline $\mathrm{N}_{1-3}$ & 41 & 58.54 & 43.90 & & \\
\hline \multicolumn{6}{|l|}{ M stage } \\
\hline $\mathrm{M}_{0}$ & 48 & 69.57 & 54.35 & 6.77 & 0.009 \\
\hline $\mathrm{M}_{1}$ & 10 & 41.67 & 8.33 & & \\
\hline \multicolumn{6}{|c|}{ Histological differentiation } \\
\hline High/moderate & 5 & 36.00 & 0 & 6.02 & 0.014 \\
\hline Poor & 53 & 67.92 & 49.06 & & \\
\hline \multicolumn{6}{|l|}{ TAP-1 expression } \\
\hline Positive & 25 & 80.00 & 60.00 & 11.77 & 0.001 \\
\hline Negative & 33 & 51.52 & 33.33 & & \\
\hline \multicolumn{6}{|l|}{ TAP-2 expression } \\
\hline Positive & 27 & 81.48 & 62.96 & 19.38 & 0.000 \\
\hline Negative & 31 & 48.39 & 29.03 & & \\
\hline \multicolumn{6}{|l|}{ HLA-I expression } \\
\hline Positive & 29 & 82.76 & 65.52 & 18.90 & 0.000 \\
\hline Negative & 29 & 44.83 & 24.14 & & \\
\hline
\end{tabular}

NPC, nasopharyngeal carcinoma; TAP, transporters associated with antigen processing; HLA, human leukocyte antigen.

blood of NPC patients was $33.41 \pm 10.04 \%$ (Fig. 2A), which was lower compared to that of the normal subjects, which was $40.15 \pm 3.56 \%$ (Fig. $2 \mathrm{~B})(\mathrm{P}<0.05$, Fig. $2 \mathrm{E})$. There was no significant difference between the NPC and control groups regarding $\mathrm{CD}^{+} \mathrm{T}$ cells $(25.32 \pm 8.29$ vs. $22.89 \pm 2.24 \%, \mathrm{P}>0.05$, Fig. 2C, D and E). The ELISA results indicated that the expression of IL-10 in NPC was higher compared to that in the control group $(13.12 \pm 1.23$ vs. $3.69 \pm 1.03 \mathrm{ng} / \mathrm{ml}$, respectively; $\mathrm{P}<0.05$, Fig. 2E).

Association between TAP-1, TAP-2 and HLA-I status and clinical variables. As shown in Table III, the low expression of TAP-1, TAP-2 and HLA-1 was significantly associated with TNM stage, lymph node metastasis and distant metastasis $(\mathrm{P}<0.05)$. No association was observed between their expression with age and gender $(\mathrm{P}>0.05)$.

Correlations of TAP-1, TAP-2 and HLA-I expression with $C D 4^{+} T$ cells, $C D 8^{+} T$ cells and IL-10. In order to elucidate whether TAP-1, TAP-2 and HLA-I expression affected
$\mathrm{CD}^{+} \mathrm{T}$ cells, $\mathrm{CD}^{+} \mathrm{T}$ cells and IL-10, we divided the 58 NPC patients into TAP-1-positive and -negative groups, TAP-2-positive and -negative groups and HLA-I-positive and -negative groups and then assessed the proportion of $\mathrm{CD}^{+} \mathrm{T}$ and $\mathrm{CD}^{+} \mathrm{T}$ cells and the expression of IL-10 in the subgroups. As shown in Table IV, there was no significant difference between the positive and negative subgroups regarding the expression of $\mathrm{CD}^{+} \mathrm{T}$ cells $(33.19 \pm 9.2$ vs. $33.35 \pm 8.05 \% ; 33.58 \pm 6.4$ vs. $32.52 \pm 5.2 \%$; and $34.34 \pm 6.58$ vs. $30.22 \pm 3.49 \%$, respectively; $\mathrm{P}>0.05)$. The percentage of $\mathrm{CD}^{+} \mathrm{T}$ cells was higher in the positive compared to the negative TAP-1, TAP-2 and HLA-I groups $(27.93 \pm 4.04$ vs. $18.43 \pm 2.37 \% ; 28.47 \pm 3.62$ vs. $19.18 \pm 2.11 \%$; and $31.35 \pm 4.72$ vs. $16.65 \pm 2.07 \%$, respectively; $\mathrm{P}<0.05$ ). The expression of IL-10 was lower in the positive compared to the negative TAP-1, TAP-2 and HLA-I groups $(9.87 \pm 1.24$ vs. $16.20 \pm 1.48 \mathrm{ng} /$ $\mathrm{ml} ; 8.93 \pm 0.56$ vs. $16.04 \pm 1.75 \mathrm{ng} / \mathrm{ml}$; and $6.28 \pm 0.86$ vs. $17.99 \pm 2.01 \mathrm{ng} / \mathrm{ml}$, respectively; $\mathrm{P}<0.05)$.

Follow-up and univariate survival analysis. A total of 58 patients received standard treatment and were regularly 
Table VI. Multivariate Cox regression analysis.

\begin{tabular}{lcccc}
\hline Variable & Wald & OR & $95.0 \%$ CI & P-value \\
\hline Age & 0.595 & 1.290 & $0.675-2.465$ & 0.440 \\
Gender & 0.014 & 1.037 & $0.570-1.886$ & 0.904 \\
TNM stage & 0.004 & 0.952 & $0.220-4.128$ & 0.948 \\
Lymph node metastasis & 0.112 & 1.155 & $0.497-2.687$ & 0.737 \\
Distant metastasis & 4.598 & 2.609 & $0.971-5.974$ & 0.041 \\
Histological differentiation & 0.016 & 0.922 & $0.262-3.242$ & 0.899 \\
TAP-1 expression & 0.005 & 1.071 & $0.168-6.819$ & 0.942 \\
TAP-2 expression & 0.412 & 1.925 & $0.260-14.250$ & 0.521 \\
HLA-I expression & 4.557 & 2.586 & $0.389-8.186$ & 0.042
\end{tabular}

OR, odds ratio; CI, confidence interval; TAP, transporters associated with antigen processing; HLA, human leukocyte antigen.

followed up. The Kaplan-Meier analysis was used to analyze single factors considered to affect disease progression including age, gender, TNM stage, lymph node metastasis or lack thereof, distant organ metastasis or lack thereof, pathological type, TAP-1 expression, TAP-2 expression and HLA-I expression. We observed that clinical stage, lymph node metastasis, distant organ metastasis, histological differentiation, TAP-1 expression, TAP-2 expression and HLA-I expression exerted a significant effect on the overall survival of NPC patients (Fig. 3 and Table $\mathrm{V}, \mathrm{P}<0.05$ ).

Multivariate survival analysis. Since the factors mentioned above were shown to exert a significant effect on the survival of NPC patients, a multivariate analysis was performed to assess the independent predictive value of each of these factors for overall survival. Of note, distant metastasis and HLA-I expression status were shown to be potential independent prognostic factors for NPC patients $(\mathrm{P}=0.041$ and $\mathrm{P}=0.042$, respectively, Table VI).

\section{Discussion}

During the tumor immune response process, the MHC class I molecules (mainly HLA-I) play a crucial role in the elimination of virally infected and transformed cells by cytotoxic $\mathrm{T}$ cells (CTLs). The CTLs recognize virally infected or malignant $\mathrm{T}$ cells by foreign peptides presented on the cell surface in association with class I antigens. The HLA-I antigen processing and presentation pathway starts with proteins being degraded by the proteasome, which consists of multiple catalytic subunits (mainly LMP-2 and -7). The peptides are then translocated across the endoplasmic reticulum (ER) membrane via the antigen-processing subunits TAP-1 and -2 . The HLA-I heavy chain is synthesized in the ER, where it forms a complex with $\beta_{2} \mathrm{M}$. The HLA-I/ $\beta_{2} \mathrm{M}$ complex then interacts with TAP-associated peptides and facilitates peptide loading into HLA-I $/ \beta_{2} \mathrm{M} /$ peptide complexes, which are transported to the surface.

TAP plays a pivotal role in the peptide loading of the HLA-I molecules and is therefore essential for their expression on the cell surface. Thus, the transport of the HLA-I complexes to the cell surface may be prevented if TAP is malfunctioning, leading to antigen not being recognized by CTLs and escaping the immune supervision (13-15). The absence of TAP-1, LMP-2, LMP-7 and HLA-I have been reported to occur in small-cell lung carcinoma (16), colorectal cancer, breast cancer (17), malignant melanoma, malignant tumors of the head and neck (18) and malignant brain tumors (19) and may represent a mechanism of tumor escape from the control of the immune system. An increase in the expression of LMP-2, LMP-7 and HLA-I may be induced if TAP transfection is performed.

In our study, the expression of TAP-1, TAP-2 and HLA-I in NPC were distinctly reduced. In the peripheral blood of NPC patients, the expression of IL-10, which has immunosuppressive function, was increased and the percentage of $\mathrm{CD}^{+} \mathrm{T}$ cells, which help B lymphocytes secrete antibodies, was decreased. The percentage of the $\mathrm{CD} 8^{+} \mathrm{T}$ cells, which are crucial in eliminating the infected or malignant $\mathrm{T}$ cells had no detectable change. However, we observed that the percentage of $\mathrm{CD}^{+} \mathrm{T}$ cells exhibited a consistently positive correlation with the expression of TAP-1, TAP-2 and HLA-I, whereas the expression of IL-10 had a negative correlation with the expression of TAP-1, TAP-2 and HLA-I in NPC. These results suggest that the reduction in the expression of TAP-1, TAP-2 and HLA-I may contribute to the immunosuppression associated with in NPC, which may help tumor cells escape immune surveillance (20).

An association between the downregulation of TAP-1, TAP-2 and HLA-I expression and cancer prognosis has been reported in a wide range of malignancies (21-24). The correlation between TAP-1, TAP-2 and HLA-I and prognosis in NPC has been investigated (25). Our data demonstrated that the downregulation of the expression of TAP-1, TAP-2 and HLA-I became more prominent in more advanced clinical stages. The Cox regression model indicated that HLA-I expression and distant metastasis were independent prognostic factors. Distant metastasis was the major cause of mortality in patients with NPC, even following successful locoregional control with radiotherapy or/ and chemotherapy. According to a previous study, $\sim 11-36 \%$ of NPC patients with controlled locoregional disease will develop distant metastasis (26). Distant metastasis was shown to be a negative prognostic factor in the present study, although the difference was not considered statistically significant $(\mathrm{P}=0.041)$. 
Several factors may have affected the results: i) distant metastasis may not have been diagnosed by pathological examination. It has been suggested that ${ }^{18} \mathrm{~F}$-fluorodeoxyglucose-positron emission tomography/computed tomography is the most sensitive, specific and accurate modality for distant metastasis staging of NPC; ii) gender, pretreatment quality of life variables, treatment, metastatic spread to different organs and short-term treatment response may affect the prognosis of NPC with distant metastasis $(27,28)$; iii) an increase in the follow-up of NPC cases is required. Of note, the expression of HLA-I, but not that of TAP-1 and/or TAP-2, was an independent prognostic factor in NPC. The HLA-I molecules play a central role in antigen submission, during which TAP molecules are involved in antigen transport and the antigen/HLA assembly. Thus, the downregulation of HLA-I expression correlates in part with the decrease in the TAPs (12). This study suggested that the downregulation of HLA-I expression was particularly associated with a poor prognosis in NPC patients. Due to the limited patient sample, it could not be determined whether this constitutes a biological property or is due to the limited data availability.

In conclusion, we demonstrated that the expression of TAP-1, TAP-2 and HLA-I were downregulated in NPC and this downregulation may contribute to immunosuppression in NPC patients. Of note, distant metastasis and HLA-I expression may be considered as independent prognostic factors in NPC. Further studies are required to elucidate the molecular mechanisms through which TAP-1, TAP-2 and HLA-I expression affect immunity and investigate the possibility of designing a biological treatment that will enhance HLA-I molecule expression in NPC patients.

\section{Acknowledgements}

We would like to thank the patients and healthy donors for participating in this study. This study was supported in part by grants from the National Natural Science Foundation of China (no. 81260312), the Research Project Foundation of Health Science and Technology of Yunnan Province (no. 2011WS0068), the Technological Plan of Society Development of Yunnan Province (Fundamental Research Program) (no. 2009ZC119M) and the Technological Plan of Society Development of Yunnan Province (Key Fundamental Research Program) (no. 2009CC026).

\section{References}

1. Yang T, McNally BA, Ferrone S, Liu Y and Zheng $P$ A single-nucleotide deletion leads to rapid degradation of TAP-1 mRNA in a melanoma cell line. J Biol Chem 278: 15291-15296, 2003

2. Vujanovic L, Whiteside TL, Potter DM, Chu J, Ferrone S and Butterfield LH: Regulation of antigen presentation machinery in human dendritic cells by recombinant adenovirus. Cancer Immunol Immunother 58: 121-133, 2009.

3. Young LS and Rickinson AB: Epstein-Barr virus: 40 years on. Nat Rev Cancer 4: 757-768, 2004.

4. Gallicchio L, Matanoski G, Tao XG, et al: Adulthood consumption of preserved and nonpreserved vegetables and the risk of nasopharyngeal carcinoma: a systematic review. Int J Cancer 119: 1125-1135, 2006.

5. Bei JX, Jia WH and Zeng YX: Familial and large-scale case-control studies identify genes associated with nasopharyngeal carcinoma. Semin Cancer Biol 22: 96-106, 2012.

6. Jia WH and Qin HD: Non-viral environmental risk factors for nasopharyngeal carcinoma: a systematic review. Semin Cancer Biol 22: 117-126, 2012.
7. Shao JY, Zhang Y, Li YH, et al: Comparison of Epstein-Barr virus DNA level in plasma, peripheral blood cell and tumor tissue in nasopharyngeal carcinoma. Anticancer Res 24: 4059-4066, 2004.

8. Chan AT, Lo YM, Zee B, et al: Plasma Epstein-Barr virus DNA and residual disease after radiotherapy for undifferentiated nasopharyngeal carcinoma. J Natl Cancer Inst 94: 1614-1619, 2002.

9. Bar-Sela G, Kuten A, Minkov I, Gov-Ari E and Ben-Izhak O: Prevalence and relevance of EBV latency in nasopharyngeal carcinoma in Israel. J Clin Pathol 57: 290-293, 2004.

10. Raab-Traub N: Epstein-Barr virus in the pathogenesis of NPC. Semin Cancer Biol 12: 431-441, 2002.

11. Horikawa T, Yoshizaki T, Kondo S, Furukawa M, Kaizaki Y and Pagano JS: Epstein-Barr virus latent membrane protein 1 induces Snail and epithelial-mesenchymal transition in metastatic nasopharyngeal carcinoma. Br J Cancer 104: 1160-1167, 2011.

12. Li W, Deng XM, Wang CX, et al: Down-regulation of HLA class I antigen in human papillomavirus type 16 E7 expressing $\mathrm{HaCaT}$ cells: correlate with TAP-1 expression. Int J Gynecol Cancer 20: 227-232, 2010.

13. Li XL, Zhang D, Knight D, et al: Priming of immune responses against transporter associated with antigen processing (TAP)-deficient tumours: tumour direct priming. Immunology 128: 420-428, 2009.

14. Everett MW and Edidin M: Tapasin increases efficiency of MHC I assembly in the endoplasmic reticulum but does not affect MHC I stability at the cell surface. J Immunol 179: 7646-7652, 2007.

15. Tourkova IL, Shurin GV, Ferrone S and Shurin MR: Interferon regulatory factor 8 mediates tumor-induced inhibition of antigen processing and presentation by dendritic cells. Cancer Immunol Immunother 58: 567-574, 2009.

16. Singal DP, Ye M and Bienzle D: Transfection of TAP 1 gene restores HLA class I expression in human small-cell lung carcinoma. Int J Cancer 75: 112-116, 1998.

17. Wang X, Ni J, Hsu CL, et al: Reduced expression of tocopherol-associated protein (TAP/Sec14L2) in human breast cancer. Cancer Invest 27: 971-977, 2009.

18. Lopez-Albaitero A, Nayak JV, Ogino T, et al: Role of antigen-processing machinery in the in vitro resistance of squamous cell carcinoma of the head and neck cells to recognition by CTL. J Immunol 176: 3402-3409, 2006.

19. Facoetti A, Nano R, Zelini P, et al: Human leukocyte antigen and antigen processing machinery component defects in astrocytic tumors. Clin Cancer Res 11: 8304-8311, 2005.

20. Tanaka K, Tsuchikawa T, Miyamoto M, et al: Down-regulation of human leukocyte antigen class I heavy chain in tumors is associated with a poor prognosis in advanced esophageal cancer patients. Int J Oncol 40: 965-974, 2012.

21. Cresswell AC, Sisley K, Laws D, Parsons MA, Rennie IG and Murray AK: Reduced expression of TAP-1 and TAP-2 in posterior uveal melanoma is associated with progression to metastatic disease. Melanoma Res 11: 275-281, 2001.

22. Seliger B, Atkins D, Bock M, et al: Characterization of human lymphocyte antigen class I antigen-processing machinery defects in renal cell carcinoma lesions with special emphasis on transporter-associated with antigen-processing down-regulation. Clin Cancer Res 9: 1721-1727, 2003.

23. Han LY, Fletcher MS, Urbauer DL, et al: HLA class I antigen processing machinery component expression and intratumoral T-cell infiltrate as independent prognostic markers in ovarian carcinoma. Clin Cancer Res 14: 3372-3379, 2008.

24. Liu Q, Hao C, Su P and Shi J: Down-regulation of HLA class I antigen-processing machinery components in esophageal squamous cell carcinomas: association with disease progression. Scand J Gastroenterol 44: 960-969, 2009.

25. Moss DJ, Khanna R, Sherritt M, Elliott SL and Burrows SR: Developing immunotherapeutic strategies for the control of Epstein-Barr virus-associated malignancies. J Acquir Immune Defic Syndr 1: S80-S83, 1999.

26. Chua ML, Ong SC, Wee JT, et al: Comparison of 4 modalities for distant metastasis staging in endemic nasopharyngeal carcinoma. Head Neck 31: 346-354, 2009.

27. Wang CT, Cao KJ, Li Y, Xie GF and Huang PY: Prognosis analysis of nasopharyngeal carcinoma patients with distant metastasis. Chin J Cancer 26: 212-215, 2007 (In Chinese).

28. Fang FM, Tsai WL, Chien CY, et al: Pretreatment quality of life as a predictor of distant metastasis and survival for patients with nasopharyngeal carcinoma. J Clin Oncol 28: 4384-4389, 2010. 